\section{I B R I}

w w w. libridergi.org
Kitap Tanıtımı, Eleştiri ve Çeviri Dergisi

Journal of Book Notices, Reviews and Translations

Volume III (2017)

K. IREN, Ç. KARAÖZ - Ö. KASAR (Haz.), Persler:

Anadolu'da Kudret ve Görkem (The Persians: Power

and Glory in Anatolia). İstanbul 2017. Yapı Kredi

Yayınları, 424 sayfa. ISBN: 9789750840012

\title{
Emre SALMAN
}

OPEN 2

access journals

Libri: Kitap Tanıtımı, Eleştiri ve Çeviri Dergisi'nde bulunan içeriklerin tümü kullanıcılara açık, serbestçe/ücretsiz "açık erişimli” bir dergidir. Kullanıcılar, yayıncıdan ve yazar(lar)dan izin almaksızın, dergideki kitap tanıtımlarını, eleştirileri ve çevirileri tam metin olarak okuyabilir, indirebilir, dağıtabilir, çıktısını alabilir ve kaynak göstererek bağlantı verebilir.

Libri, uluslararası hakemli elektronik (online) bir dergi olup değerlendirme süreci biten kitap tanıtımları, eleştiriler ve çeviriler derginin web sitesinde (libridergi.org) yıl boyunca ilgili sayının içinde (Volume III: Ocak-Aralık 2017) yayımlanır. Aralık ayı sonunda ilgili yıla ait sayı tamamlanır.

Dergide yayımlanan eserlerin sorumluluğu yazarlarına aittir.

Atıf Düzeni: E. Salman, Historia: Antikçağda Araştırma Fikrinin Doğuşu. Hazırlayanlar: K. İren, Ç. Karaöz, Ö. Kasar, Libri III (2017) 485-489.

DOI: $10.20480 /$ Ibr.2017038

Geliş Tarihi: 10.11.2017 | Kabul Tarihi: 28.11.2017

Elektronik Yayın Tarihi: 24.12.2017

Editörya: Phaselis Research Project www.libridergi.org 


\section{K. İREN, Ç. KARAÖZ - Ö. KASAR (Haz.), Persler: Anadolu'da Kudret ve Görkem (The Persians: Power and Glory in Anatolia). İstanbul 2017. Yapı Kredi Yayınları, 424 sayfa. \\ ISBN: 9789750840012}

Emre SALMAN*

Anadolu Tarihi'nin Pers Dönemi'ni kapsayan kitap Perslerin Anadolulu uyruklarıyla nasıl bir yönetişim sistemi meydana getirdiklerini alanında uzman araştırmacıların yazdıkları makalelerle irdeliyor. Aslında bu kitap Anadolu Tarihi'ni en erken devirlerden itibaren ele alan Anadolu Uygarlıkları Serisi'nin (Anatolian Civilizations Series) altıncı kitabı olarak ortaya çıkmış ve serinin diğer kitapları gibi Anadolu'nun tarihsel dokusunu arkeolojik, nümizmatik, epigrafik ve tarihsel kanıtlardan yola çıkarak bir bütünlük içerisinde incelemiştir. 23,5×33 ebadında kuşekağıdına basıımış olan ve Türkçe-Ingilizce olarak çift dilli yayımlanan kitap; Önsöz [Foreword] (VIII-IX), Anadolu Topraklarında 200 yıl ve Çok Kültürlülük [200 years of cultural pluralism on Anatolian soil] (X-XI), Küçük Sözlük [Glossary] (411-412) ve Dizin [Index] (413-424) başlıklarıyla birlikte yirmi iki makaleden oluşmaktadır. Önsöz [Foreword], kitabın oluşturulmasında katkıları bulunan Tüpraş adına kurumun genel müdürü Ibrahim Yelmenoğlu'nun imzasını taşırken Anadolu Topraklarında 200 yıl ve Çok Kültürlülük [200 years of cultural pluralism on Anatolian soil] başlığı kitabın editörleri Kaan İren, Çiçek Karaöz ve Özgün Kasar tarafından böylesine bir çalışmanın amacını açıklamak için kaleme alınmıştır.

Tomris Bakır'ın yazdığı Anadolu'da Perslerin Izinde [Tracing the Persians' Footsteps in Anatolia] (2-9) isimli çalışma kitabın ilk makalesidir. Yazar, bu çalışmasında Anadolu'daki Perslerin iki önemli yönetim merkezi olan Sardeis ve

\footnotetext{
* MA., Akdeniz Üniversitesi, Akdeniz Uygarlıkları Araştırma Enstitüsü, Akdeniz Eskiçağ Araştırmaları Anabilim Dalı, Antalya. emresalmn@gmail.com
} 
Daskyleion satraplık merkezlerinin arkeologlar tarafından gerçekleştirilen kazı sürecini ana hatlarıyla özetlemektedir. Ardından, ilkin Pers imparatorluğunun kurucusu Büyük Kyros ve soyunu; imparatorluğun gerek yönetim gerek toplumsal açıdan nasıl bir yapıya sahip olduğunu ele alan Persler Kimdir? [Who are the Persians?] (12-20) başlıklı çalışma dünyada Persler üzerine bir otorite olan Pierre Briant'a aittir ve kitabın ikinci makalesini oluşturmaktadır. Fahri ışık tarafından hazırlanan Perslerden Önce Anadolu [Anatolia Before the Persians] (24-49) başlıklı çalışma kitabın üçüncü makalesidir. Yazar bu çalışmasında Anadolulu bir bakış açısıyla Urartuları, Yeni Hititleri, Phrygialıları, Lydialıları, Karialıları, Lykialıları ve İonialıları ele ele alarak bu halklardan özellikle İonialılara erken devir Anadolu kültürünü Perslere kadar taşımaları hasebiyle dikkat çeker. Böylece Pers önceki Anadolu'nun genel bir portresi çıkartılmış olur. Pers Hâkimiyeti Altında Anadolu Halkları [The Anatolian People under the Persian Rule] (52-61) isimli Frédéric Maffre'ye ait çalışma kitabın dördüncü makalesidir. Bu çalışmada, Anadolu'ya Perslerin ilk girişlerinden itibaren yerel halk ve geçlerle nasıl bir yönetişim meydana getirdikleri ve ortak Anadolu-Pers kültürünün tarihsel süreç içerisinde nasıl bir yol izlediği ele alınmaktadır. Kitabın, Eric A. Raimond tarafından kaleme alınan beşinci makalesi Pers Anadolusu'nda Tanrılar ve Halklar: Lykia Tanrıları Örneği [Gods and Peoples in Persian Anatolia: the Case of Lycian Deities] (66-75) olarak isimlendirilmiştir. Burada yazar, Letoon Üç Dilli Yazıtı (Steli) örneğinden hareketle Lykia Bölgesi halkının inançlarını değerlendirmektedir. Pers imparatorluğunun kuruluşundan itibaren meydana gelen siyasî olayların Anadolu özelinde ele alındığı Anadolu'da Persler: Savaş, İsyan ve Diplomasi [Persians in Anatolia: War, Rebellion and Diplomacy] (78-99) başlıklı altıncı makale ise Sevgi Sarıkaya ve Murat Arslan tarafından kaleme alınmıştır. Persler Dönemi'nde Anadolu'da Para ve Ticaret [Money and Trade During the Persian Period in Anatolia] (102-133) isimli yedinci makale Oğuz Tekin'e aittir. Yazar bu çalışmasında, Perslerin Sardeis'i ele geçirdikleri tarihten itibaren sikke darp ettiklerini ancak bu darpların genelde Batı AnadoIu'da kullanıldıklarını belirtmektedir. Ayrıca sikkelerin kullanım alanları ve Anadolu ticarî hayatına etkileri de tartışılan konulardan biri olarak dikkat çekmektedir. Kitabın sekizinci makalesi Murat Arslan tarafından kaleme alınan iskender'in Küçük Asya Seferi ve Isssos Muharebesi: Antikçağ Tarihine Yön Veren Bir Muharebenin Portresi [The Asia Minor Campaign of Alexander and the Battle of Issus Portrait of a Battle that Shaped Ancient History] (136-158) olarak isimlendirilmiştir. Yazar bu çalışmasında, Büyük İskender'in Perslerle yaptığı üç 
çarpışmanın ikincisi olan İssos Muharebesi'ni gelişim aşamalarıyla birlikte mitolojik anlatılardan soyutlayarak ele almaktadır. Ayrıca makalenin ilk sayfalarında tarihçilerin, siyasetçilerin, entelektüellerin ve tabi ki toplumun Büyük iskender'e nasıl yaklaştıkları genel hatlarıyla özetlenmiştir. Suat Ateşlier'e ait ve kitabın dokuzuncu makalesi olan Anadolu'da Pers Dönemi Yapıları [Architecture During the Persian Period in Anatolia] (162-171) başlıklı çalışmada, Pers Dönemi Anadolusu'ndaki mimarî faaliyetlerin Arkhaik Dönem'e nazaran daha sönük olduğu belirtildikten sonra MÖ VI. ile IV. yüzyıl arası mimarî gelişmeler mezar yapıları üzerinden ele alınmaktadır. Pers kralî imgelerinden olan paradeisosun Batı Anadolu'da kurulmalarını ve bu imgeyi satrapların ne amaçla kullandıklarını ele alan Yeryüzü Cennetleri: Pers Bahçeleri ve Paradeisosları [Earthly Paradises: Persian Gardens and Paradeisoi] (174-183) başlıklı kitabın onuncu makalesi ise Hülya Bulut'a aittir. Kitabın on birinci makalesi Anadolu'da Pers Etkili Taş Plastik Eserler [Persian Influence on Stone Carving in Anatolia] (186-201) adı Gürcan Polat'a ait çalışmadır. Yazar, Anadolu'daki Pers plastik taş eserlerini genellikle nekrolojik kalıntılar (zira en fazla bu tip kalıntılar gelmiştir günümüze) üzerinden değerlendirmektedir. Özellikle eserlerde Anadolulu yerel yöneticilerin Pers kralî imgelerini nasıl kullandığı kabartmalardaki sahneler incelenerek betimlenmektedir. Polyksena Lahdi'nin incelendiği kitabın on ikinci makalesi Figen Çevirici-Coşkun'a aittir ve Polyksena Lahdi: Bir Pers soylusunun Lahdi mi? [The Polyxena Sarcophagus: A Persian Aristocrat's Sarcophagus?] (204-221) olarak isimlendirilmektedir. Sedef Çokay-Kepçe'nin kaleme aldığı Anadolu'da Bulunmuş Pişmiş Toprak Akhaimenid Kâse ve Phialeler: Genel Bir Değerlendirme [Achaemenid Terracotta Bowls and Phiale Found in Anatolia: An Overview] (224-234) kitabın on üçüncü makalesini oluşturmaktadır. Yazar bu çalışmasında, Anadolu'nun doğusundan batısına kadar ele geçen arkeolojik veriler ışığında Akhaimenid kâse tipinin yayılım alanlarını belirlemeye çalışmaktadır. Ayrıca Akhaimenid kâse tipinin yayılım alanının aynı zamanda Pers yaşam kültürünün yayılım alanı olduğunu da belirtmiştir. Akhaimenid döneminden kalma dekorasyon eşyaları, kaplar ve takılar özelinde Anadolu'daki Pers izlerinin ele alındığı İnci Delemen'e aittir ve Anadolu'da Pers Etkili Prestij Nesneleri (Insignia) [Prestige Objects (Insignia) with Persian Influences in Anatolia] (238-251) olarak isimlendirilmiştir. Kitabın on beşinci makalesi ise Deniz Kaplan'a ait olan Anadolu'da Pers dönemi Mühürleri [Seals from Achaemenid Anatolia] (254-267) olarak isimlendirilmiş çalışmadır. Burada yazar tarafından, öncelikle Anadolu'dan ele geçmiş Pers dönemi mühürlerinin 
buluntu yerleri ve araştırılmaları ardından ise bu mühürlerin kullanımında gözetilen amaç ve tipolojileri genel hatlarıyla anlatılmaktadır. Atinalıların Gözünden Anadolu'da Pers Varlığı [The Persian Presence in Anatolia-An Athenian Perspective] (270-280) olarak isimlendirilen on altıncı makale Margaret C. Miller'e aittir. Yazar bu çalışmasında, vazo resimleri ve lahitlerdeki tasvirlerden yola çıkarak ilkçağ Hellenlerinin Perslere bakış açısını çözümlemeye çalışmaktadır. Adnan Diler'in kaleme aldığı kitabın on yedinci makalesi Anadolu-Pers Dönemi Sanatında Ikonografi: Gelenek, Gerçeklik ve Paradoks [Iconography in Anatolian-Persian Art: Tradition, Political Realism and Paradox] (284-305) olarak isimlendirilmiştir. Burada Anadolulu yerel eserlerin Perslerle ilişkiler doğrultusunda doğu etkisi taşıdıkları söylendikten sonra bu sanat eserlerinin belli başı ikonografileri betimlemekte ve yorumlamaktadır. Kitabın on sekizinci makalesi Nicholas Cahill'in kaleme aldığı Lydia Satraplığı [The Satrapy of Lydia] (308-329) olarak isimlendirilmiştir. Yazar bu çalışmasında, Perslerden önce de halihazırda Anadolu'nun yönetim merkezi olan Sardeis kenti ve çevresindeki Lydia Bölgesi'nin Pers fetihleriyle ne gibi bir dönüşüm geçirdiğini yönetim organizasyonu, kentleşme ve el sanatları gibi çeşitli konu başlıklarıyla irdemektedir. Kaan İren ve Handan Yıldızhan'ın ortaklaşa kaleme aldığı makale Pers Daskyleionu: Güney Marmara Bölgesi'nde Bir Satraplık Merkezi [Persian Dascyleum: a Satrapal Center in Soutern Marmara Region] (332-345) olarak isimlendirilmektedir. Bu makalede yazarlar, Daskyleion'un jeopolitik konumu ve tarihî coğrafyasından başlayarak Pers imparatorluğu döneminde nasıl bir satraplık merkezi olduğunu ele almaktadırlar. Kitabın yirminci makalesi Olivier Can Henry'e aittir ve Hyssaldomos'un Oğlu Hekatomnos: Pers Tarihinde Benzersiz Bir Kişilik [Hecatomnus, son of Hyssaldomus: A Unicum in Persian History] (350-365) olarak isimlendirilmiştir. Yazar bu çalışmasında, Hekatomnidlerin kökeni, hakimiyet kurdukları bölge ve hanedanın kurucusu Hekatomnos'un siyasî faaliyetleri, ardında bıraktığı arkeolojik, nümizmatik ve epigrafik envanteri inceleyerek yorumlarda bulunmaktadır. Paphlogonia Bölgesi'ndeki Pers hakimiyetinin başlangııından MÖ IV. yüzyıla kadarki tarihsel süreci ele alan ve sonrasında bölgedeki Pers dokusuna değinen Batı Karadeniz Bölgesi'nde Pers izleri [Persian Traces in the West Black Sea Region] (368-387) başıklı, kitabın yirmi birinci makalesi F. Eray Dökü'ye aittir. Kitabın son makalesi ise Stuart Blaylock'a ait olan ve Fırat Üzerinde Tille Höyük'te Akhaimenid Tabakası ve Güneydoğu Anadolu'da Akhaimenid Arkeolojisi Için Diğer Bulgular [The Achaemenid Level at Tille Höyük on the Euphrates and Other Evidence for 
Achaemenid Archaeology in South-East Anatolia] (390-407) ismini taşıyan çalışmadır. Yazar bu makalede, Tille Höyük'ün X. Tabakası olarak tanımlanan dokunun Akhaimenid dönemine tarihlendiğini belirtir ve bu tabakadan günümüze ulaşan arkeolojik envanterin Perslerle ilişkisi üzerinde durmaktadır.

Geniş bir coğrafyaya yayılmış ve farklı halklar üzerinde hâkimiyet sağlamış en erken örneklerden biri olan Pers İmparatorluğu yaklaşık iki yüz yıl boyunca Anadolu'yu (Küçük Asia) yönetti. Perslerin bu iki yüz yıl boyunca farklı kültürlere karşı daima itidalle yaklaşmaları yönetimlerinin devamlılı̆̆ını sağlayan en önemli etkendi. Yirmi beş yüzyıl sonra bile farklııklara, ötekiliklere, bizden olmayanlara karşı gösteremediğimiz bu itidal, Perslerin bize halen öğretecek bir şeyleri olduğunu gösteriyor. Zengin Anadolu topraklarında MÖ VI. yüzyılın ortalarından başlayıp MÖ IV. yüzyılın ikinci yarısına kadar devam eden ve Anadolu-Pers olarak adlandırılan bir kültür evresinin oluşmasını sağlayan bu dönemin izlerini başta arkeolojik eserler olmak üzere sanatın her alanında görmek mümkündür. Kitapta bu eserlerin fotoğraflarına yer verilmesi kitabı tematik açıdan oldukça renklendirmiştir. Ayrıca kitabın sonuna eklenen Sözlük (Glossary) başı̆̆ı altında kitap içerisindeki teknik terimlerin yer alması, herhangi bir sözlük yardımı olmaksızın okuyucuya gereken bilgiyi vermesi sebebiyle faydalı olmuştur. Neticede alanında Türkçe'de yayımlanmış en kapsamlı kitap olma özelliği taşıyan eserin Persler üzerine yapılacak gelecekteki çalışmalara da öncülük edeceği şüphesizdir. 